\title{
Collagen remodelling by airway smooth muscle is resistant to steroids and
} $\beta_{2}$-agonists

\author{
J.E. Bourke, X. Li, S.R. Foster, E. Wee, H. Dagher, J. Ziogas, T. Harris, \\ J.V. Bonacci and A.G. Stewart
}

ABSTRACT: Bi-directional interactions between airway smooth muscle (ASM) and the altered extracellular matrix (ECM) may influence airway wall remodelling and ASM function in asthma. We have investigated the capacity of cultured human ASM to reorganise the structure of threedimensional collagen gels and the effects of endothelin (ET)-1 and agents used to treat asthma.

Human ASM cells were cast in type I collagen gels. Reductions in gel area over $72 \mathrm{~h}$ were determined in the absence and presence of ET-1 and potential inhibitors, steroids and $\boldsymbol{\beta}_{2}-$ adrenoceptor agonists. Changes in gel wet weights and hydroxyproline content were measured and ASM gel morphology was examined by scanning electron microscopy.

Cell density-dependent reductions in gel area were augmented by ET-1, mediated via $\mathrm{ET}_{A}$ receptors. This process was not associated with ASM contraction or proliferation, but was consistent with ASM tractional remodelling and migration leading to collagen condensation rather than collagen degradation within gels. The collagen remodelling by ASM was unaffected by salbutamol and/or budesonide.

This study demonstrates an additional potential role for ASM in ECM regulation and dysregulation in airways disease that is resistant to steroids and $\beta_{2}$-adrenoceptor agonists. Therapy-resistant collagen condensation within ASM bundles may facilitate ECM-ASM interactions and contribute to increased internal airways resistance.

KEYWORDS: Airway smooth muscle, asthma, collagen, endothelin-1, glucocorticoid, steroid resistance

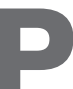

rominent features of airway wall remodelling (AWR) in asthma include the accumulation of airway smooth muscle (ASM) and an expansion and alteration in the composition of extracellular matrix (ECM), including an increased abundance of collagen type I $[1,2]$. Increased bi-directional interactions between ASM and the altered pericellular ECM may occur due to these changes. These interactions may be influenced by endothelin (ET)-1, since ET-1 can increase both ASM proliferation and collagen secretion, in addition to its better characterised potent bronchoconstrictor actions [3].

The contribution of ASM to fibrogenic changes in ECM synthesis and turnover in asthma has been regarded as minor compared with its contractile role mediating airways hyperresponsiveness [4, 5]. In contrast, the contribution of airway fibroblasts to sub-epithelial fibrosis in AWR is well documented
$[6,7]$, with differentiation to a myofibroblast phentoype associated with increased collagen synthesis [8]. However, phenotypic modulation of ASM cells from a contractile to a synthetic-proliferative state $[5,9]$ is also associated with release of an array of pro-inflammatory cytokines and chemokines and the secretion of multiple ECM proteins, including collagen [4].

Even if the contribution of ASM to the ECM bulk is modest, ECM can influence critical ASM functions implicated in asthma. In vitro evidence suggests that degradation of the pericellular ECM environment of the ASM could reduce muscle load to facilitate increased muscle shortening [10] while an expanded and stiffer ECM has been associated with reduced distensibility of the airways [11].

In addition, the altered ECM surrounding ASM could achieve significance through autocrine/paracrine

This article has supplementary material available from www.erj.ersjournals.com

AFFILIATIONS

Dept of Pharmacology, University of Melbourne, Victoria, Australia.

CORRESPONDENCE

J.E. Bourke

Dept of Pharmacology

University of Melbourne

Victoria

Australia 3010

E-mail: janeew@unimelb.edu.au

Received:

Jan 162009

Accepted after revision:

June 092010

First published online:

July 012010 
influences on noncontractile ASM functions, including proliferation, migration and synthesis of secretory products. Culture of ASM on collagen type I has been shown to induce a greater proliferative response to a variety of mitogens and to increase production of eotaxin, RANTES and granulocyte-macrophage colony-stimulating factor [12-15].

The capacity of glucocorticoids to modulate ASM-ECM interactions may also be changed in the presence of an altered ECM. Glucocorticoids can exert antiproliferative, antimigratory and anti-inflammatory effects on both fibroblasts and ASM [16, 17], but the steroid sensitivity of these responses is impaired in the presence of denatured (nonfibrillar) type I collagen [13]. In addition, increased ECM production in response to profibrotic mediators is also steroid resistant [18].

ASM-ECM interactions may also lead to collagen remodelling through cell-mediated reorganisation of the surrounding matrix structure. This process has been extensively studied using human fetal lung (HFL)-1 and adult bronchial fibroblasts seeded in three-dimensional type I collagen gels [19-21] as a model of both wound healing and tissue remodelling. Fibroblast-induced reductions in gel area are generally described as gel "contraction", and can be accelerated or increased in magnitude by diverse mediators including ET-1 and transforming growth factor- $\beta$ [19-21]. Of particular relevance is the observation that an increase in collagen density mediated by fibroblasts can be further augmented by glucocorticoids [20].

Although ASM has also been shown to cause reductions in collagen gel area [19], neither the mechanism for this process nor its regulation by asthma mediators or glucocorticoids has been explored in detail. Given the potential influence of ASMECM interactions to contribute to changes in ASM synthetic and contractile function implicated in airway disease, we have used type I collagen gels seeded with human ASM to investigate the potential of these cells to contribute to remodelling of the surrounding ECM. The effects of ET-1 and histamine on this process have been assessed in the presence of various inhibitors and selective receptor antagonists to explore the mechanisms underlying ASM-dependent gel contraction. The effects of glucocorticoids and $\beta_{2}$-adrenoceptor agonists have also been examined to explore potential modulation of collagen remodelling by agents used in the treatment of asthma.

\section{METHODS}

\section{Cell culture}

Human ASM cultures were generated from bronchi from macroscopically normal airways, resected from lung transplant recipients or donors and from pneumonectomy specimens. ASM was microdissected from the bronchus wall and enzymatically digested with collagenase $\left(1 \mathrm{mg} \cdot \mathrm{mL}^{-1}\right)$ and elastase $\left(0.5 \mathrm{mg} \cdot \mathrm{mL}^{-1}\right)$ [22].

Cells were maintained at $37^{\circ} \mathrm{C}$ in $5 \% \mathrm{CO}_{2}$ in air in Dulbecco's Modified Eagles Medium (DMEM) (with $2 \mathrm{mM}$ L-glutamine, $0.25 \%$ bovine serum albumin (BSA), $100 \mathrm{U} \cdot \mathrm{mL}^{-1}$ penicillin $\mathrm{G}$, $100 \mu \mathrm{g} \cdot \mathrm{mL}^{-1}$ streptomycin, $2 \mu \mathrm{g} \cdot \mathrm{mL}^{-1}$ amphotericin $\mathrm{B}$ and $10 \%$ $\mathrm{vol} /$ vol fetal bovine serum). Cells passaged weekly at a 1:4 split ratio were used between passages 3 and 14 .

\section{Measurement of calcium mobilisation}

The effects of ET-1 $(0.1-100 \mathrm{nM})$ or histamine $(0.1-100 \mu \mathrm{M})$ on intracellular calcium levels were assessed as previously described [23]. ASM were plated at a density of $2 \times 10^{4}$ cells $\cdot \mathrm{mL}^{-1}$

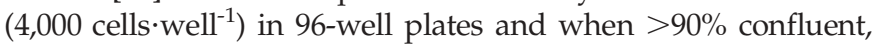
DMEM was removed and cells washed twice with hydroxyethyl piperazine ethane sulphonic acid (HEPES)-buffered saline (HBS) buffer (145 mM NaCl, $5 \mathrm{mM} \mathrm{KCl}, 1 \mathrm{mM} \mathrm{MgSO}{ }_{4} .7 \mathrm{H}_{2} \mathrm{O}$, $10 \mathrm{mM}$ D-glucose, $10 \mathrm{mM}$ HEPES, free acid, $2 \mathrm{mM} \mathrm{CaCl}_{2} \cdot 2 \mathrm{H}_{2} \mathrm{O}$, $2.5 \mathrm{mM}$ probenecid, $37^{\circ} \mathrm{C}, \mathrm{pH}$ 7.4). The buffer was then replaced with HBS containing $1 \mu \mathrm{M}$ Fluo- 4 for $60 \mathrm{~min}$ at $35^{\circ} \mathrm{C}$, before washing. Changes in intracellular $\mathrm{Ca}^{2+}$ concentration evoked by increasing concentrations of agonist were measured over a 2 min period using the Flexstation II (Molecular Devices, Sunnyvale, CA, USA).

\section{Preparation of collagen gels}

Flasks of confluent ASM were serum deprived for $72 \mathrm{~h}$ in incomplete medium (fetal calf serum-free DMEM, $0.25 \%$ weight/vol BSA) to cause growth arrest. Cells were then displaced with $0.5 \%$ trypsin, collected and centrifuged $(1,500 \times g, 5 \mathrm{~min})$, before resuspension at cell densities of $\leqslant 3.75 \times 10^{6}$ cells $\cdot \mathrm{mL}^{-1}$ in four-times concentrated incomplete DMEM. The cell suspension was immediately mixed thoroughly with fibrillar type I collagen $\left(1.6 \mathrm{mg} \cdot \mathrm{mL}^{-1}\right.$ dialysed rat tail tendon collagen extracted as previously described [24], at $4^{\circ} \mathrm{C}$ ) in a 1:3 ratio and gels were cast in 24-well culture plates

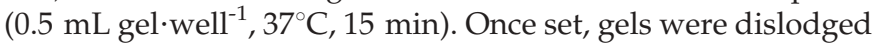
by adding $1 \mathrm{~mL}$ incomplete DMEM, transferred to six-well plates, suspended freely floating in $3 \mathrm{~mL}$ incomplete DMEM and incubated for $\leqslant 72 \mathrm{~h}$.

\section{Drug treatments and measurement of gel area}

The effects of ET-1 (0.1-10 nM) or histamine $(0.01-100 \mu \mathrm{M})$ on ASM-mediated changes in gel area were assessed. The ET-1 antagonists $\mathrm{BQ} 123\left(\mathrm{ET}_{\mathrm{A}}\right.$-selective) and $\mathrm{BQ788}$ (ET $\mathrm{B}_{\mathrm{B}}$-selective) were used to ascertain whether ET-1 was mediating gel contraction via $\mathrm{ET}_{\mathrm{A}}$ or $\mathrm{ET}_{\mathrm{B}}$ receptors, respectively. The activity of these agents was evaluated at $0.1-10 \mu \mathrm{M}$, as this concentration range spanned the published $\mathrm{pA}_{2}$ values of 6.9-7.4 for BQ123 and 6.9 for BQ788 [25]. Inhibitors of phosphoinositide 3kinase (PI3K) (LY294002, $20 \mu \mathrm{M})$, p38 mitogen-activated protein kinase (p38 MAPK) (SB203580, $30 \mu \mathrm{M})$ and MEK 1/2 (U0126, $50 \mu \mathrm{M}$ ) were added at concentrations known to cause inhibition in ASM (reviewed in [5]). The effects of cytochalasin $\mathrm{D}(100 \mathrm{nM})$ and latrunculin $\mathrm{A}(2 \mu \mathrm{M})$ were assessed at concentrations shown to inhibit actin polymerisation within collagen gels [26]. cAMP-elevating agents, 8-bromo-cAMP $(300 \mu \mathrm{M})$ and salbutamol (10-1,000 nM), and glucocorticoids, dexamethasone (10-1000 nM) and budesonide (100 nM), were also tested at appropriate concentrations [13, 22]. All potential inhibitors were added $30 \mathrm{~min}$ prior to ET-1 (10 nM) where applicable.

ASM gel areas were initially determined by the diameter of 24 well culture plates in which they were cast. Areas were then measured at intervals of up to $72 \mathrm{~h}$ with an image analyser system (Kodak Image Station 440CF; Eastman Kodak, Rochester, NY, USA). The coefficient of variation determined by repeated measures of area of the same gel was $<3 \%$. 


\section{Scanning electron microscopy of ASM gels}

ASM cells in collagen gels fixed in $2.5 \%$ glutaraldehyde in $0.1 \mathrm{M}$ PBS for $2 \mathrm{~h}$ were rinsed $(3 \times 15 \mathrm{~min})$ and postfixed in $1 \%$ osmium tetroxide for $1 \mathrm{~h}$. After rinsing (PBS, $3 \times 15 \mathrm{~min}$ ), specimens were dehydrated in a graded ethanol series $(30,50$, 70,90 and 100\% ethanol in water, $20 \mathrm{~min}$ each), critically point dried in a Bal-Tec 030 CPD (Bal-Tec A.G., Balzers, Lichtenstein), and mounted onto $25 \mathrm{~mm}$ aluminium stubs with doublesided carbon tabs. Samples were gold-coated in an Edwards S150B sputter coater (Edwards High Vacuum Ltd, Crawley, West Sussex, UK) and imaged in a Philips XL30 (Eindhoven, the Netherlands) field-emission scanning electron microscope at $2 \mathrm{kV}$.

\section{Measurements of ASM density using MTT assays}

ASM-containing gels were incubated with 3-[4, 5-dimethylthiazol2-yl]-2,5-diphenyltetrazolium bromide (MTT, final concentration $1 \mathrm{mg} \cdot \mathrm{mL}^{-1}$, overnight, $37^{\circ} \mathrm{C}$ ), washed (two times with PBS) and digested with collagenase $\left(0.25 \mathrm{mg} \cdot \mathrm{mL}^{-1}, 37^{\circ} \mathrm{C}, 2 \mathrm{~h}\right)$. After centrifugation $(10,000 \times g, 5 \mathrm{~min}), 400 \mu \mathrm{L}$ dimethyl sulfoxide was added to the cell pellet to solubilise the blue formazan product, which was then quantified by reading absorbance at $550 \mathrm{~nm}$ (method modified from [27]). The linear relationship between increasing cell density and absorbance measured in gels seeded with ASM at densities of up to $3.75 \times 10^{6}$ cells $\cdot \mathrm{mL}^{-1}$ was maintained after $72 \mathrm{~h}$ (supplementary fig. A).

\section{Measurements of supernatant matrix metalloprotease-2 activity}

Gel supernatants were assayed for proteolytic matrix metalloprotease (MMP) activity by gelatin zymography, using conditioned media from human cultured ASM as an internal control. Image capture and densitometry were performed using Kodak 1D software (Eastman Kodak) as previously described [28].

Measurements of gel weights and hydroxyproline content Gels were collected to determine wet weights and acid lysates of freeze-dried gels were subsequently assayed for total hydroxyproline as an index of collagen content, as previously described [29].

\section{Measurement of ASM migration}

Migration of ASM was assessed with a wound assay [30]. Cells were grown to confluence in 24 well plates, then serum-starved in incomplete media for $24 \mathrm{~h}$ before treatment with $200 \mathrm{nM}$ Mitotracker Green (Molecular Probes for $2 \mathrm{~h}$ ). The cells were washed twice with PBS and fresh incomplete media was added. The cell layer was scraped with a pipette tip and cells were then incubated in the absence and presence of ET-1 $(10 \mathrm{nM})$ for $18 \mathrm{~h}$. The wound edge was viewed and photographed using live cell imaging (Leica DMI 6000B; Leica, Milan, Italy) at 30-min intervals. Changes in wound area with time were analysed using VideoSavant ${ }^{\mathrm{TM}}$ software (IO Industries Inc., London, ON, Canada).

\section{Statistical analysis}

All data were expressed as the mean \pm SEM of the response from $\mathrm{n}$ different primary cultures, each from a different donor, and analysed using Graph Pad Prism ${ }^{\mathrm{TM}}$ software version 4.0 (GraphPad Software, La Jolla, CA, USA). Effects of time and either cell density or drug concentration were tested by two-way repeated measures ANOVA on raw area values. Effects of inhibitors were examined by paired t-tests or by oneway repeated measures ANOVA, followed by Bonferroni post hoc tests for multiple comparisons. Differences were considered to be statistically significant when $\mathrm{p}<0.05$.

\section{RESULTS}

\section{ASM-mediated collagen remodelling is time- and cell- density dependent}

To determine whether ASM could mediate collagen remodelling, gels were prepared in the absence and presence of ASM cells at varying numerical density. There was no change in area of cell-free collagen gels over $72 \mathrm{~h}$ (fig. $1 \mathrm{a}$ and b). Reductions of up to $50 \%$ in area were evident in gels prepared using ASM at increasing cell densities ranging $0.625-3.75 \times 10^{6}$ cells $\cdot \mathrm{mL}^{-1}$ (fig. 1c).

The morphology of ASM within gels was examined using scanning electron microscopy. Multiple interactions between ASM and surrounding collagen fibres were evident immediately after gels were cast $(t=0$, fig. 2a). Although ASM cells initially appeared rounded, they were clearly elongated after $72 \mathrm{~h}$ (fig. 2b). Increased density of collagen fibres was evident within the gels with time (fig. $2 a$ and b) and with increasing ASM density (fig. 2c and d).
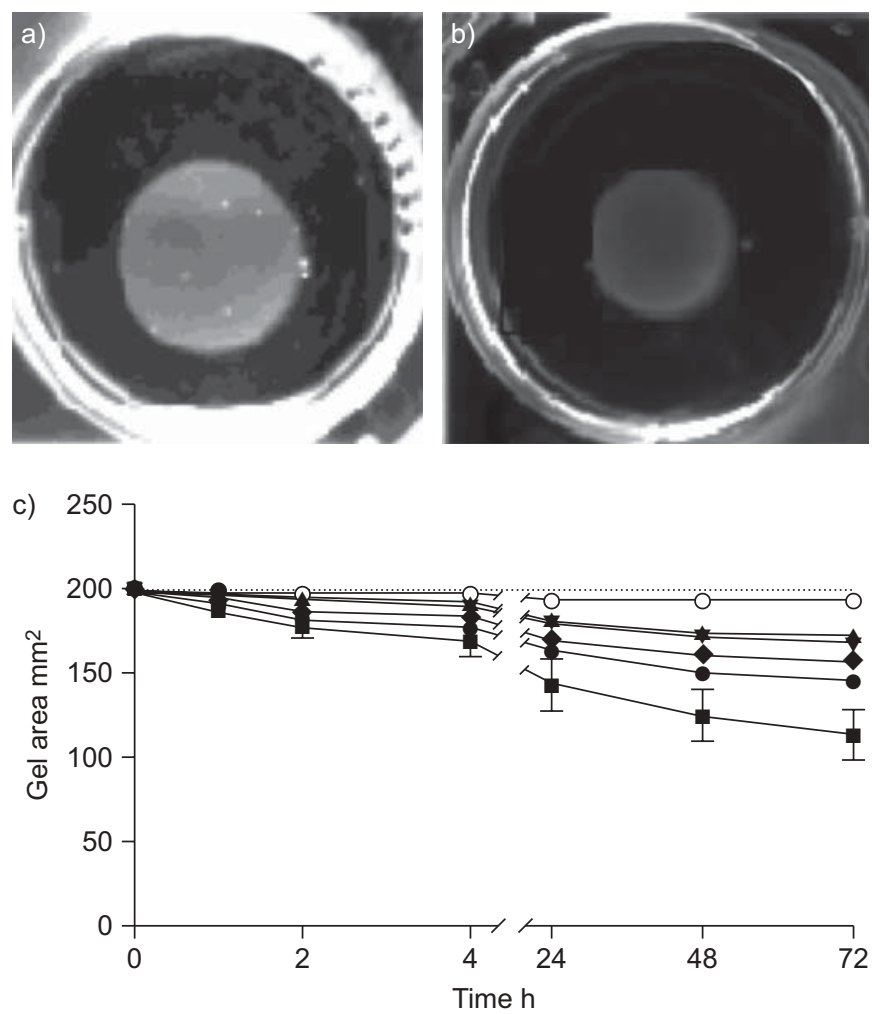

FIGURE 1. Collagen gel area is reduced with time; a) $t=0$ and b) $t=72$ and c) cell density in airway smooth muscle (ASM) gels. Gel areas showing effect of ASM cell density $\left(0.625-3.75 \times 10^{5}\right.$ cells $\left.\cdot \mathrm{mL}^{-1}\right)$ over $72 \mathrm{~h}$ are expressed as mean $\pm \operatorname{SEM}(n=5)$ with error bars only shown for selected data sets for clarity. Cell density $\left(\times 10^{5}\right.$ cells $\left.\cdot \mathrm{mL}^{-1}\right)$ : $0: 0 ; \mathbf{\Lambda}: 0.625 ; \mathbf{V}: 1.25 ; \bullet: 1.875 ; \bullet: 2.5 ; \mathbf{\square}: 3.75$ .....: represents initial gel area. Two-way ANOVA with repeated measures, $p<0.001$ for time, $p<0.05$ for cell density 

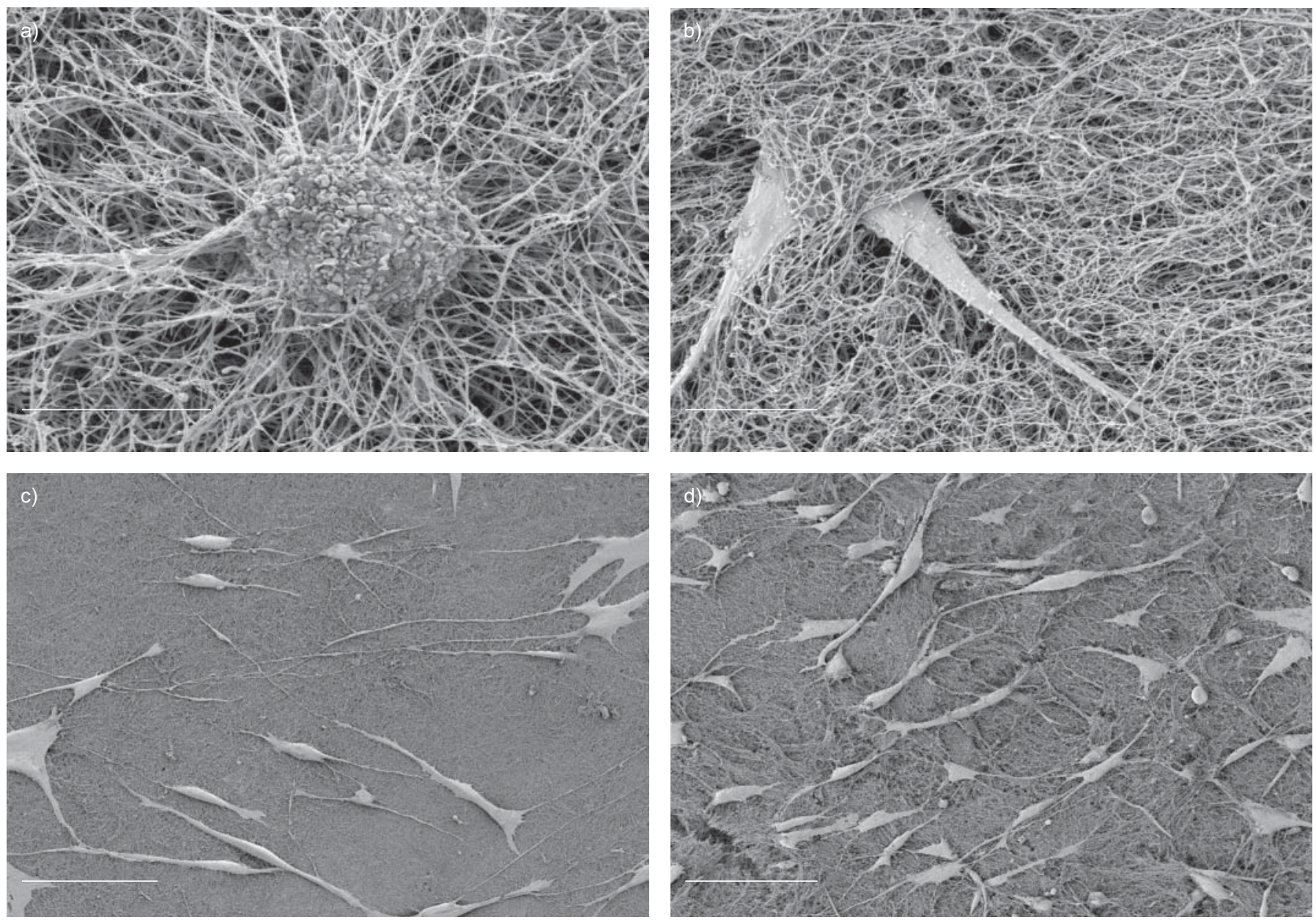

FIGURE 2. Collagen density is increased with time and airway smooth muscle (ASM) cell density. Scanning electron micrographs of collagen gels seeded with ASM were prepared as described in the Methods. Gels seeded at an ASM density of $2.5 \times 10^{5}$ cells $\cdot \mathrm{mL}^{-1}$ for a) $t=0$ and $\left.b\right) t=72 \mathrm{~h}$. Scale bars $=10 \mu \mathrm{M}$. Gels seeded at ASM densities of c) $0.625 \times 10^{5}$ cells $\cdot \mathrm{mL}^{-1}$ (low density) and d) $3.75 \times 10^{5} \mathrm{cells} \cdot \mathrm{mL}^{-1}$ (high density), both at $\mathrm{t}=72 \mathrm{~h}$. Scale bars $=100 \mu \mathrm{M}$.

Subsequent studies were performed at an ASM density of $2.5 \times 10^{6}$ cells $\cdot \mathrm{mL}^{-1}$, at which initial gel areas were reduced by $13 \pm 3 \%$ within the first $4 \mathrm{~h}(\mathrm{n}=19, \mathrm{p}<0.05$ in comparison with $\mathrm{t}=0$ ). This density was chosen to permit assessment of augmentation or inhibition of sub-maximal reductions in gel area.

\section{Collagen remodelling is augmented by $E T-1$ via $E T_{A}$ receptors, but may be independent of active muscle contraction}

To determine the potential contribution of active contraction of ASM to ASM-mediated reductions in gel area, the effects of ET-1 and histamine were assessed. To demonstrate that functional receptors for these contractile agonists were expressed, their effects on calcium mobilisation were measured in cultured ASM. Increases in intracellular calcium were evident within minutes in the presence of both ET-1 and histamine over the concentration ranges tested in the collagen gel assay, with ET-1 being more potent (fig. 3a).

Despite both agonists inducing calcium mobilisation, only ET-1 (0.1-10 nM) augmented collagen remodelling in a concentrationdependent manner, (fig. 3b, 2-way ANOVA; $\mathrm{p}<0.05$ ) while histamine (0.01-100 $\mu \mathrm{M})$ had no effect (fig. 3c).
The receptor-dependence of ET-1 responses were examined using the selective antagonists, BQ123 and BQ788, which display $>10,000$-fold selectivity for $\mathrm{ET}_{\mathrm{A}}$ and $\mathrm{ET}_{\mathrm{B}}$ receptors respectively [25] (fig. 3d). The antagonists did not affect gel area in the absence of ET-1 (data not shown). The response to $10 \mathrm{nM}$ ET-1 (gel area at $\mathrm{t}=72 \mathrm{~h}$ : $42 \pm 3 \%$ initial area, $\mathrm{n}=5$ ) was prevented by preincubation with the $\mathrm{ET}_{\mathrm{A}}$ antagonist $\mathrm{BQ} 123$ $(0.1 \mu \mathrm{M}, \mathrm{p}<0.05$ in comparison with ET-1 alone). In contrast, BQ788 was only effective at $10 \mu \mathrm{M}$, a concentration 100 -fold greater than its $\mathrm{pA}_{2}$ value at the $\mathrm{ET}_{\mathrm{B}}$ receptor.

\section{Collagen remodelling is not associated with ASM proliferation}

The potential contribution of ongoing ASM proliferation within gels was assessed, measuring MTT metabolism as a marker of cell density. In gels seeded with ASM at an initial density of $2.5 \times 10^{5}$ cells $\cdot \mathrm{mL}^{-1}$, absorbance values for conversion of MTT were not altered during collagen remodelling $(2.3 \pm 0.4$ at $\mathrm{t}=0$ in comparison with $2.7 \pm 0.6$ at $\mathrm{t}=72 \mathrm{~h}, \mathrm{n}=8$; $\mathrm{p}>0.05$, paired t-test). Although the reduction in gel area after $72 \mathrm{~h}$ was greater in the presence of ET-1, absorbance values were not increased $(2.0 \pm 0.5$ for control in comparison with $1.6 \pm 0.4$ for ET-1, $\mathrm{n}=8, \mathrm{p}>0.05$, paired t-test). 

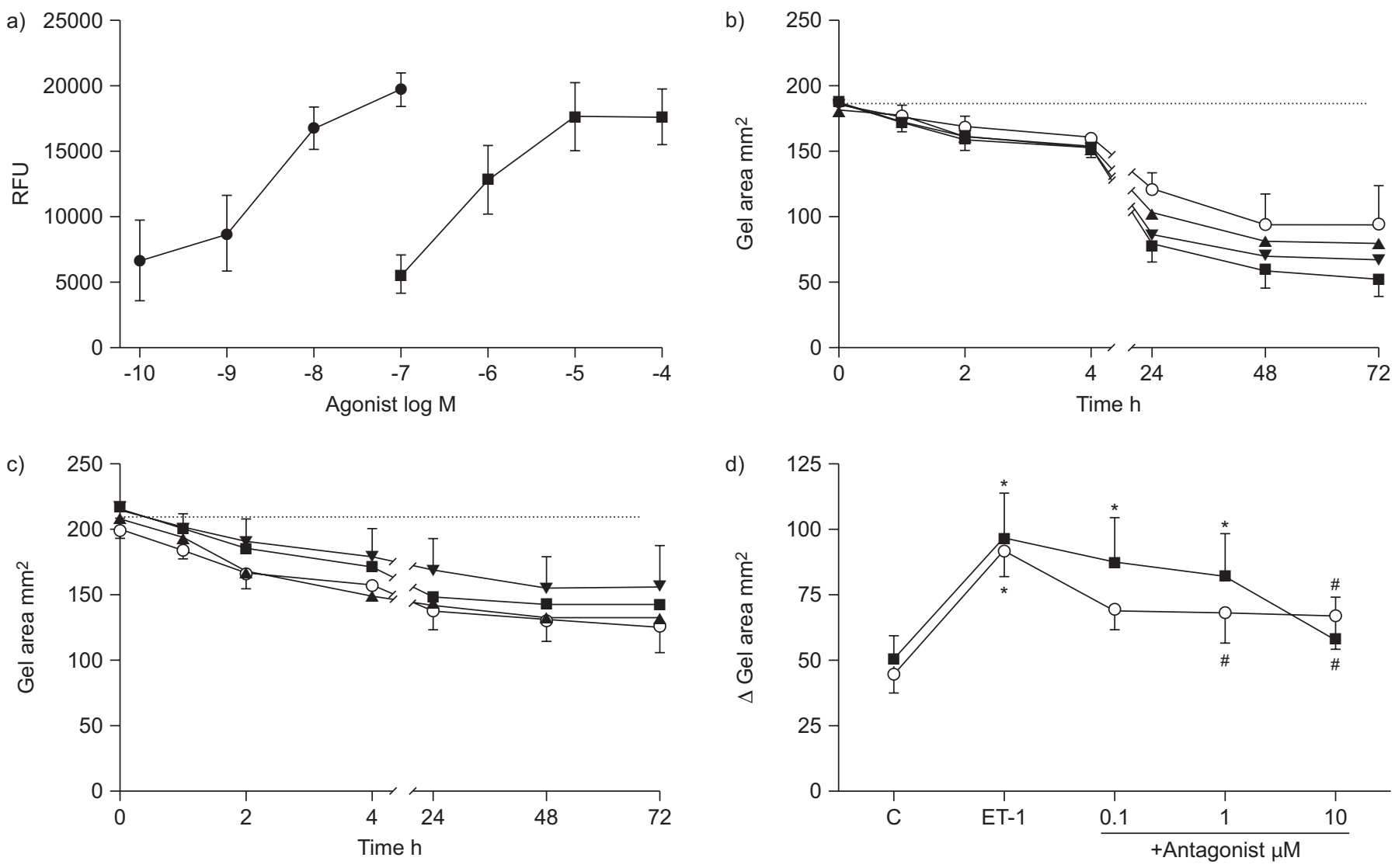

FIGURE 3. Endothelin (ET)-1, but not histamine, increases airway smooth muscle (ASM) gel contraction. a) Effect of ET-1 $\bullet 0.1-10 \mathrm{nM})$ and histamine ( $\bullet$ 0.01-10 $\mu \mathrm{M})$ on calcium mobilisation in cultured ASM. Relative fluorescence units (RFU) in response to 2 min incubation with agonists are expressed as mean \pm SEM ( $n=4$ ). Effect of $b$ ) $0.1-$ $10 \mathrm{nM}$ ET-1 (O: $0 \mathrm{nM} ; \mathbf{\Delta}: 0.1 \mathrm{nM} ; \mathbf{\nabla}: 1.0 \mathrm{nM} ; \mathbf{\square}: 10.0 \mathrm{nM})$ and c) 0.01-100 $\mu \mathrm{M}$ histamine $(0: 0 \mu \mathrm{M} ; \mathbf{\Delta}: 0.01 \mu \mathrm{M} ; \mathbf{\nabla}: 1.0 \mu \mathrm{M} ; \mathbf{\square}: 100.0 \mu \mathrm{M})$ on collagen gels seeded with ASM $\left(2.5 \times 10^{5}\right.$ cells $\left.\cdot \mathrm{mL}^{-1}\right)$. Gel areas over $72 \mathrm{~h}$ are expressed as mean \pm SEM $(E T-1 \mathrm{n}=5$, two-way ANOVA, $\mathrm{p}<0.001$; histamine $\mathrm{n}=4)$. Error bars are only shown for selected

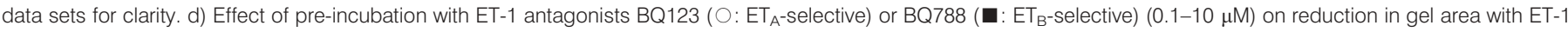
$(10 \mathrm{nM})$. Changes in gel area after $24 \mathrm{~h}$ are expressed as mean $\pm \operatorname{SEM}(\mathrm{n}=5)$ from initial areas of $203 \pm 3 \mathrm{~mm}^{2}$. C: control. .....: represents initial gel area. *: $\mathrm{p}<0.05$ in comparison with control; ${ }^{*}: \mathrm{p}<0.05$ in comparison with ET-1 alone.

\section{Collagen remodelling may be associated with ASM migration}

Wound assays in the absence and presence of ET-1 were performed to determine whether ASM migration could contribute to reductions in gel area when ASM were seeded within type I collagen gels. The reduction in wound area under control conditions over $18 \mathrm{~h}$ was increased with ET-1 treatment in three of the four ASM cultures tested (fig. 4a-e).

To examine the dependence of gel contraction on the assembly of monomeric actin into actin filaments, gels were incubated in the presence of cytochalasin D and latrunculin A. Both inhibitors of actin polymerisation inhibited gel contraction, with cytochalasin $\mathrm{D}$ reducing the change in gel area under control conditions by $42 \pm 11 \%(n=4 ; p<0.05)$. Latrunculin A was more effective, completely abolishing changes in gel area with time in the absence and presence of ET-1 (fig. $4 \mathrm{f}$ ).

The signalling pathways associated with reductions in gel area were also assessed. Inhibition of p38 MAPK by SB203580 and of PI3K by LY294002 partially inhibited reductions in gel area under control conditions by $69 \pm 21 \%$ and $31 \pm 7 \%$, respectively $(\mathrm{n}=4, \mathrm{p}<0.05$, paired $\mathrm{t}$-test). The augmented response to ET- 1 was still evident in the presence of both inhibitors, while the
MEK1/2 inhibitor U0126 had no detectable effect on collagen remodelling in the absence or presence of ET-1 (data not shown).

\section{Collagen remodelling is associated with collagen condensation not degradation}

Given the significant reduction in area of untreated ASM gels with time, changes in gel weights were also measured. There was a significant decrease in gel wet weight (gel volume) after $72 \mathrm{~h}$ by $60 \pm 11 \%$ in control gels $(\mathrm{p}<0.01$ in comparison with $t=0$, fig. 5a). This was further decreased to a loss in wet weight of $72 \pm 8 \%$ with ET-1 treatment $(\mathrm{p}<0.01$ in comparison with control, fig. 5a).

To determine if the reduced weight was due to loss of collagen as well as water, the hydroxyproline content of ASM gels was assayed. Initial hydroxyproline content averaged $7.4 \pm 0.4 \%$ of the dry gel weight $(n=4)$. Hydroxyproline could not be detected in the supernatants collected at $72 \mathrm{~h}$, and the content within gels was not changed with time or with ET-1 treatment (fig. 5b).

The role of MMPs in regulation of collagen remodelling was then examined. Both latent and active MMP-2 activity, but not MMP-9 activity, was detected in ASM gel supernatants 

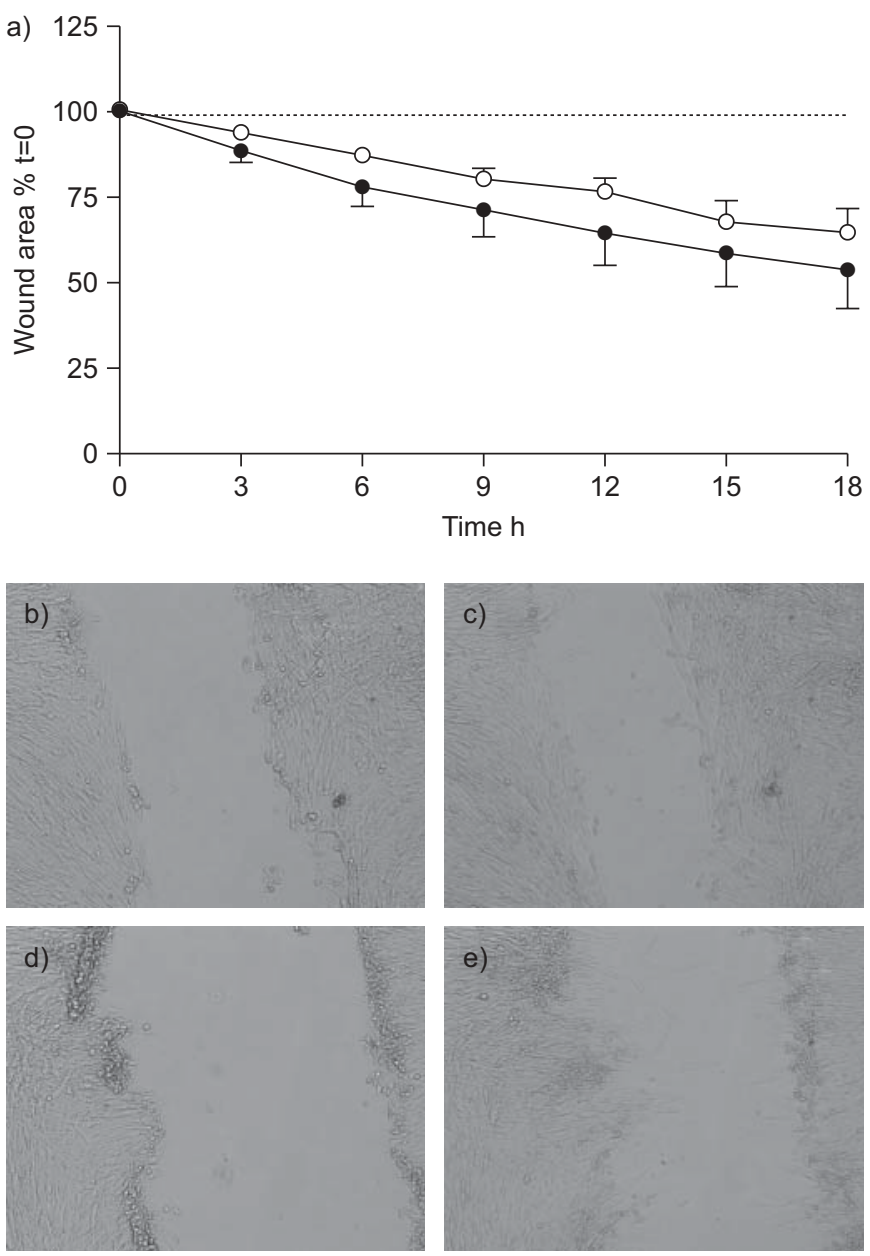

collected at $72 \mathrm{~h}$ (fig. 5c). There was no detectable increase in MMP activity in gel supernatants in the presence of ET- $1(n=8$, fig. 5c and d). Reductions in ASM gel area with time were not inhibited by the non-selective MMP inhibitor, ilomastat (fig. 5e).

\section{Collagen remodelling is not modulated by agents used to treat asthma}

The potential regulation of gel contraction by agents that relax ASM and by glucocorticoids was also assessed. Preincubation with the $\beta_{2}$-adrenoceptor agonist salbutamol did not affect the rate or extent of the reduction in gel area in control or ET-1treated gels (fig. 6a). The lack of effect of this cAMP-elevating agent was consistent with results obtained using the stable analogue 8-bromo-cAMP (fig. 6b). At concentrations up to 1,000 nM, the glucocorticoid dexamethasone did not modulate the extent of gel contraction in the absence or presence of ET-1 (table 1). Preincubation with budesonide alone or in combination with salbutamol did not affect the reduction in gel area in control or ET-1-treated gels (fig. 6c).

\section{DISCUSSION}

In the present study, reductions in the area of three-dimensional type I collagen gels seeded with ASM were cell-density dependent and increased by ET-1 acting via $\mathrm{ET}_{\mathrm{A}}$ receptors. This process did not appear to involve myocyte contraction, since it occurred over a much longer timecourse than is usually

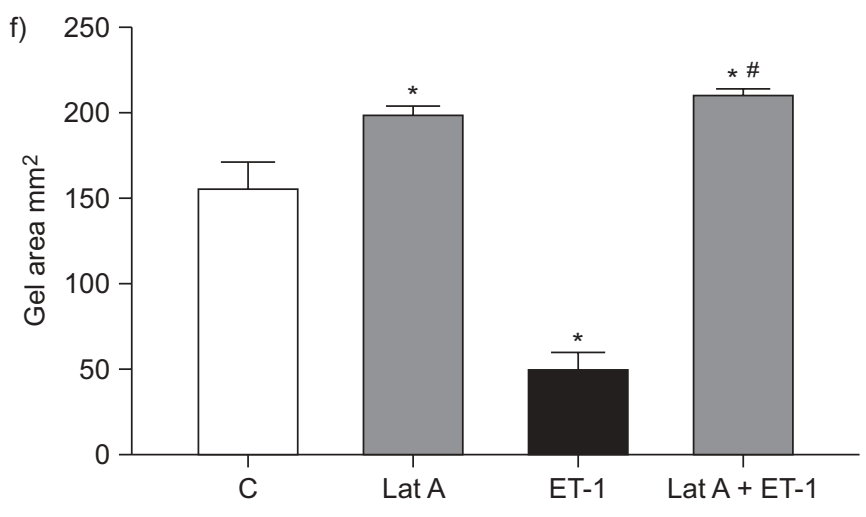

FIGURE 4. Effect of endothelin (ET)-1 on airway smooth muscle (ASM) migration, and effects of inhibitors of actin polymerisation on ASM gel contraction. a-e) Using a wound assay, migration of ASM with time were assessed in the absence and presence of $10 \mathrm{nM} E \mathrm{ET}-1$. a) Data are expressed as mean \pm SEM \% reduction in wound area over $18 \mathrm{~h}(\mathrm{n}=4)$. $\bigcirc$ : control; $\bullet \mathrm{ET}-1 ; \cdots \cdot$ : represents initial wound area. b) Control, $t=0, c)$ control, $t=18 \mathrm{~h}, \mathrm{~d})+10 \mathrm{nM} E \mathrm{ET}-1, \mathrm{t}=0, \mathrm{e})+10 \mathrm{nM}$ $E T-1, t=18 \mathrm{~h}$. f) ASM gel areas were measured in the absence and presence of $10 \mathrm{nM}$ ET-1 following 30 min pre-incubation with latrunculin $\mathrm{A}$ (Lat $\mathrm{A}, 2 \mu \mathrm{M}, \mathrm{n}=4$ ). Initial gel areas were $197 \pm 2 \mathrm{~mm}^{2}$. Gel areas at $24 \mathrm{~h}$ are expressed as mean \pm SEM. C: control. *: $p<0.05$ in comparison with control; *: $p<0.05$ in comparison with ET-1.

associated with smooth muscle shortening and force development. In addition, responses were not mimicked by histamine or prevented by agents that relax ASM. Interactions between ASM and the surrounding matrix were associated with increasing collagen fibre density rather than collagen degradation, consistent with tractional remodelling as ASM migrate through the collagen gel. This collagen remodelling was resistant to treatment with glucocorticoids, and could contribute to increased collagen density in bundles of ASM in situ in asthmatic airways. This process has the potential to influence diverse airway smooth muscle functions, including proliferation, migration and cytokine production, in addition to changing the physical properties of the cells to oppose both muscle shortening and lengthening.

Cell-mediated collagen gel contraction has been widely used as an in vitro model to study tissue remodelling and wound healing by fibroblasts in the context of fibrotic diseases [31, 32]. Very few studies have examined ASM-mediated remodelling of collagen gels $[19,33]$. Given the potential for changes in ASM-ECM interactions to influence ASM contractile and synthetic function in airways disease, we sought to explore this in vitro process and the potential mechanisms involved in its regulation.

The area of floating collagen gels seeded with ASM spontaneously reduced within several hours in the absence of an exogenous contractile stimulus. In studies using fibroblast gels, 

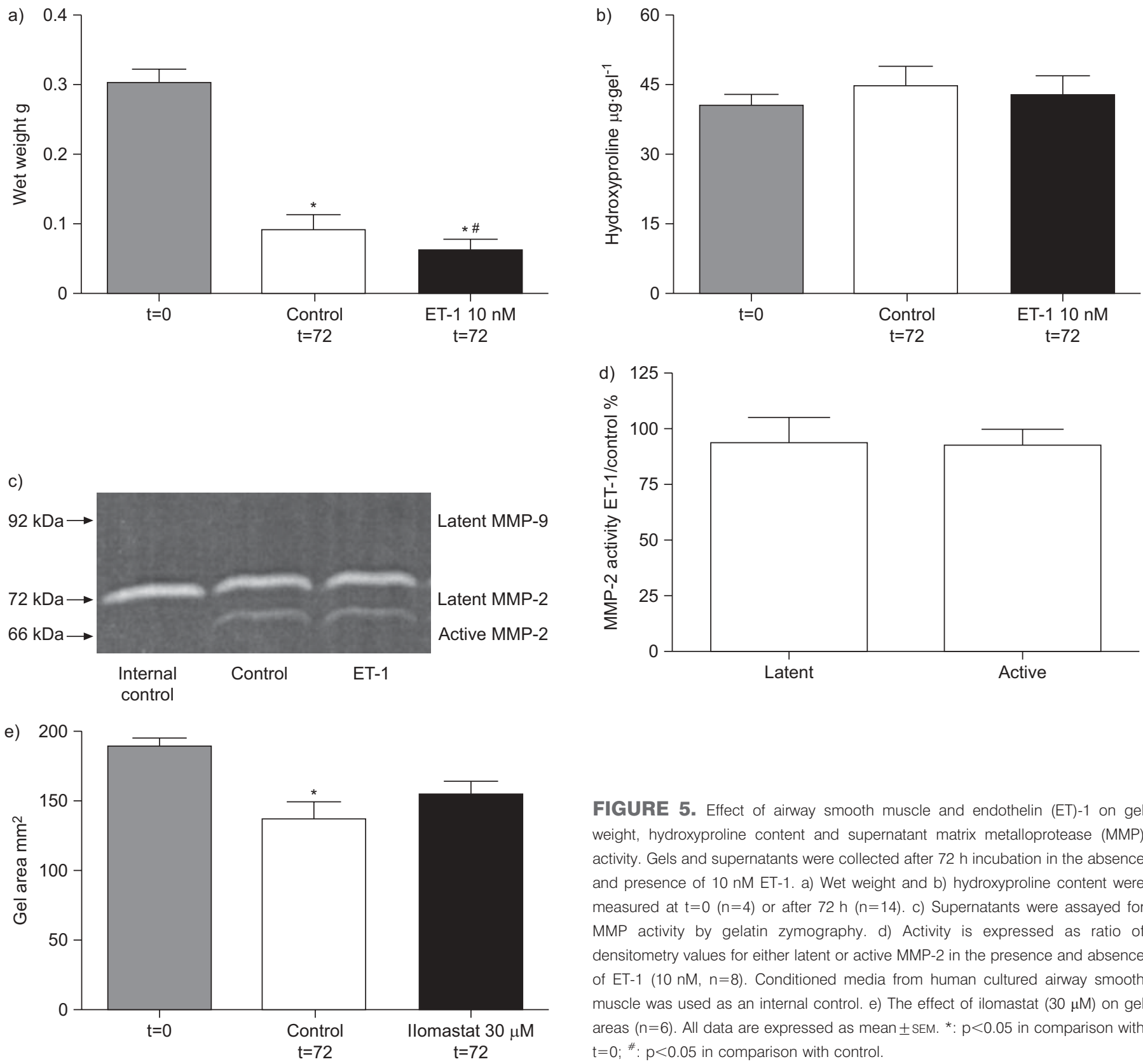

this area reduction has been attributed to the isometric tension applied to the collagen fibrils as the fibroblasts develop a myocyte-like shortening [34]. However, in the current study, the progressive reduction in ASM gel area occurring over several days in the absence of exogenous stimuli was not consistent with acute ASM shortening. Although this apparent "contraction" increased with ASM density, scanning electron microsopy in contracted gels showed that the appearance of cells within gels remained elongated irrespective of the extent of the reductions in gel area.

Despite evidence that ET-1 and histamine, both contractile agonists of ASM, could elicit calcium mobilisation in cultured ASM within minutes, the reduction in ASM gel area was augmented by ET-1, but not by histamine. These data suggest that the ET-1-induced collagen remodelling may also be

FIGURE 5. Effect of airway smooth muscle and endothelin (ET)-1 on gel weight, hydroxyproline content and supernatant matrix metalloprotease (MMP) activity. Gels and supernatants were collected after $72 \mathrm{~h}$ incubation in the absence and presence of $10 \mathrm{nM}$ ET-1. a) Wet weight and b) hydroxyproline content were measured at $t=0(n=4)$ or after $72 h(n=14)$. c) Supernatants were assayed for MMP activity by gelatin zymography. d) Activity is expressed as ratio of densitometry values for either latent or active MMP-2 in the presence and absence of ET-1 (10 nM, n=8). Conditioned media from human cultured airway smooth muscle was used as an internal control. e) The effect of ilomastat ( $30 \mu \mathrm{M})$ on ge areas $(n=6)$. All data are expressed as mean \pm SEM. *: $p<0.05$ in comparison with $t=0 ;{ }^{*}: p<0.05$ in comparison with control.

independent of active contraction of ASM within collagen gels. In support of this, the response to ET-1 was mediated via the $\mathrm{ET}_{\mathrm{A}}$ receptor, rather than the $\mathrm{ET}_{\mathrm{B}}$ receptor responsible for ASM contraction [35]. In addition, neither the stable cAMP analogue 8-bromo-cAMP nor the $\beta_{2}$-adrenoceptor agonist salbutamol that act as functional antagonists to oppose ASM contraction were able to inhibit the response. Limits to diffusion of these agents into the gels do not appear to explain this lack of effect, since reductions in gel area were shown to be inhibited by preincubation with various chemically dissimilar agents, and the response to ET-1 could be inhibited by the selective $\mathrm{ET}_{\mathrm{A}}$ antagonist $\mathrm{BQ} 123$.

The finding that histamine did not elicit a reduction in ASM gel area was contrary to a previous report [36] where a 10-20\% maximal reduction in gel area in response to $100 \mu \mathrm{M}$ histamine 

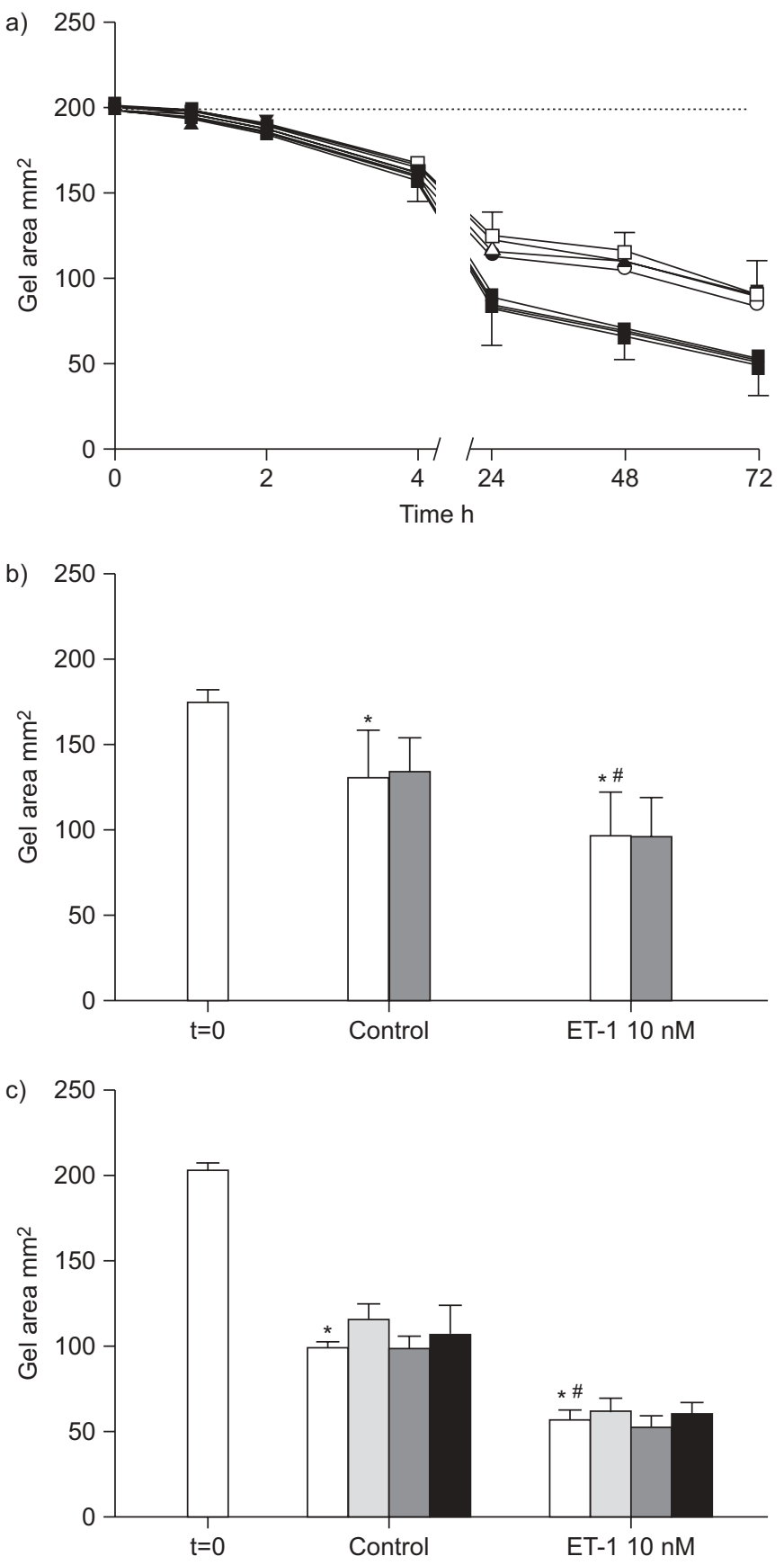

FIGURE 6. The effect of agents used to treat asthma on gel contraction. Collagen gel areas were measured in the absence (control) or presence of $10 \mathrm{nM}$ endothelin (ET)-1, following $30 \mathrm{~min}$ pre-incubation with the following agents. a) Salbutamol (10-1000 nM) $(\mathrm{n}=3)$. Control + salbutamol $(\mathrm{nM})$ : 0 : $0 ; \triangle$ : 10; $\nabla$ : 100; $\square$ : 1000. ET-1 + salbutamol (nM): -: 0; $\mathbf{\Lambda}: 10 ; \mathbf{\nabla}: 100 ; \mathbf{\square}: 1000 . \cdots \cdot$ : represents initial gel area. b) 8-bromo cAMP (Ш) $(300 \mu \mathrm{M}, 24 \mathrm{~h}, \mathrm{n}=3)$. c) Salbutamol $(\square ; 100 \mathrm{nM})$, budesonide $(\square ; 100 \mathrm{nM})$ or salbutamol + budesonide (Ш) $(24 \mathrm{~h}, \mathrm{n}=6)$. Gel areas are expressed as mean \pm SEM. *: $\mathrm{p}<0.05$ in comparison with $\mathrm{t}=0,{ }^{*}: \mathrm{p}<0.05$ in comparison with control.

was evident within $20 \mathrm{~min}$. However, in the protocol used by MAтsuмото et al. [36], gels were either left attached in the casting plate overnight (so-called "pre-stressed" gels) or had already achieved the maximum ASM-mediated reduction

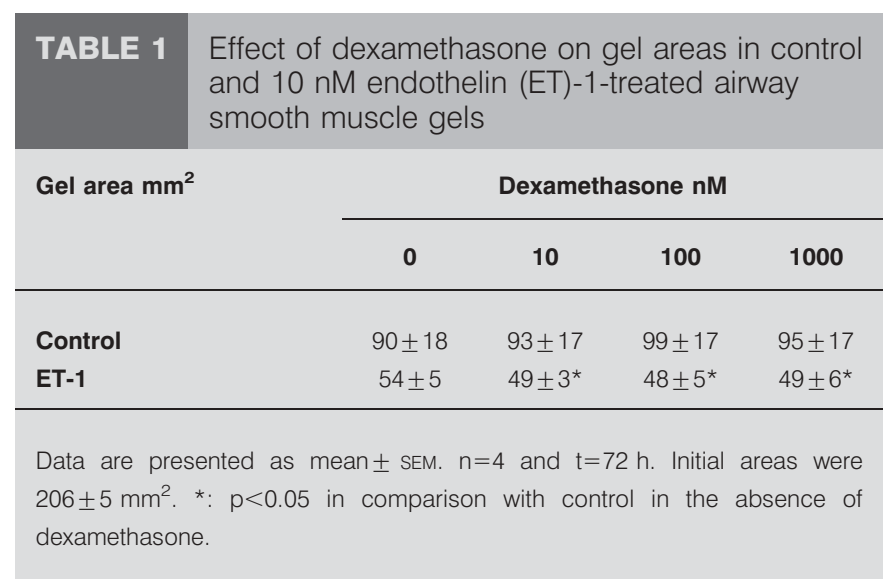

prior to drug addition. In the current study, the initial gel area was not stabilised before histamine was added so that a small acute response to histamine may not have been detected if it was occurring simultaneously upon release of the newly cast gels. Nevertheless, the ongoing progressive reductions in gel area either in the absence or presence of ET- 1 of up to $75 \%$ over several days provide evidence that active muscle contraction is not the principal mechanism for the long-term remodelling of the collagen matrix observed.

As described here with ASM gels and in previous studies using fibroblasts [31], increased cell density resulted in greater collagen remodelling. A contribution of ASM proliferation is possible, since denatured (non-fibrillar) type I collagen has been shown to enhance ASM proliferation [13, 14]. However, significant reductions in ASM gel area occurred within $24 \mathrm{~h}$, much earlier than the population doubling time of ASM of 36$48 \mathrm{~h}$ [27]. Furthermore, we have shown that the fibrillar type I collagen matrix used in these gel contraction experiments is anti-mitogenic [37].

ET-1 has been reported to elicit a small increase in DNA synthesis in ASM via $\mathrm{ET}_{\mathrm{A}}$ receptors, but appears to require comitogens for a significant increase in cell number [22, 38]. In the current study, the gel remodelling response to ET-1 was not sensitive to inhibition of the PI3K or extracellular signalregulated kinase pathways that are required for ASM proliferation [5]. Moreover, cell numbers and viability were stable over the duration of the experiments regardless of the presence of ET-1. Therefore, it appears that collagen remodelling within gels is independent of ASM proliferation.

Alternative mechanisms for reductions in the area of collagen gels include gel dehydration and/or collagen breakdown $[31,39]$. In the current study, scanning electron micrographs of contracted ASM gels showed condensation of collagen fibrils around the cells. Since the reductions in gel wet weights with time were not accompanied by reductions in hydroxyproline content, it is unlikely that the collagen fibrils were undergoing degradation. A previous study also using ASM seeded in collagen gels did not detect ECM degradation unless ASM were co cultured with monocytes or incubated with neutrophil elastase [33].

An alternative mechanism suggested for cell-mediated contraction of gels is the tractional remodelling of the collagen 
lattices occurring as a consequence of cell migration through the matrix, as has been described for fibroblasts [32, 40]. Consistent with this, we have demonstrated the capacity of ASM cultures used in the gel experiments to migrate in a wound assay. The potential contribution of migration to ASMmediated collagen remodelling is supported by the finding that the spontaneous reduction in gel area in this study was partially inhibited by SB203580, since the p38 MAPK pathway has previously been implicated in ASM migration [41]. Critically, gel contraction was also prevented by inhibitors of actin polymerisation that disrupt the cytoskeletal elements required for ASM traction and migration [42].

Remodelling of ASM collagen gels may be dependent on MMP activity to release cells from their matrix connections, as has been reported for fibroblast gels [43]. Although MMP-2 activity was detected in supernatants from ASM gels, the non-selective MMP inhibitor ilomastat did not inhibit ASM-mediated reductions in gel area. Although ET-1 has been shown to upregulate the expression of MMPs in association with vascular remodelling [44], enhanced collagen remodelling of ASM gels with ET-1 was not associated with an increase in MMP-2 activity. The findings suggest that MMP activity is not a requirement for collagen remodelling by ASM.

Given the potential influence that ASM-mediated collagen remodelling may have on diverse ASM cell functions in the airways, it was of interest to determine whether ASM gel contraction is modulated by agents used to treat asthma. The finding that salbutamol, which causes ASM relaxation, was ineffective was consistent with the evidence already presented that reductions in ASM gel area were due to collagen remodelling rather than acute ASM shortening. However, if the condensation of the collagen gels does require tractional remodelling and migration by ASM, an inhibitory effect of salbutamol may have been anticipated, since it has previously been reported that agents that mobilise cAMP inhibit migration of human ASM [45]. The lack of effect on reductions in ASM gel area requires further investigation to determine whether signalling by $\beta_{2}$-adrenoceptor agonists is impaired in ASM embedded in a 3-dimensional collagen matrix, as has been reported for glucocorticoid signalling when ASM were grown on collagen [13].

Neither dexamethasone nor budesonide regulated reductions in ASM gel area. The lack of effect of this drug class on ASMmediated collagen remodelling is consistent with other studies examining steroid modulation of diverse ASM functions. Glucocorticoids do not regulate ECM production by ASM in response to profibrotic mediators [18], and their inhibitory effects on ASM proliferation and migration are impaired in the presence of collagen, due to increased $\alpha_{2}-\beta_{1}$-integrin signalling [13]. However, the findings in ASM collagen gels are in contrast with studies showing that HFL-1 gel contraction is augmented by budesonide or hydrocortisone [20,46]. Although fibroblasts and ASM have a common action in mediating collagen remodelling, it is possible that differential regulation of this process in lung mesenchymal cells may determine their relative contributions to ongoing remodelling in health and disease.

In conclusion, this study demonstrates an additional potential role for ASM in the dynamic regulation of ECM and its dysregulation in airways disease that is resistant to the effects of both glucocorticoids and $\beta_{2}$-adrenoceptor agonists. This celldependent process could increase the collagen density in bundles of ASM in situ, and further facilitate ASM-ECM interactions, with the potential for profound effects on airway function. Ultimately, ASM-mediated gel contraction may provide a useful screen for identification of selective agents to prevent cell-mediated collagen remodelling in lung diseases including asthma.

\section{SUPPORT STATEMENT}

This work was supported by the National Health and Medical Research Council (Grants 299823, 509001, 509239); Contributing to Australian Scholarship and Science (CASS) Foundation; ANZ Medical Research and Technology in Victoria Fund, Australian Academy of Science and Asthma Foundation of Victoria.

\section{STATEMENT OF INTEREST}

A statement of interest for A.G. Stewart can be found at www.erj. ersjournals.com/site/misc/statements.xhtml

\section{ACKNOWLEDGEMENTS}

We thank J. Wilson (Dept Allergy, Immunology and Respiratory Medicine, Alfred Hospital, Melbourne, Australia) and the anatomical pathologists at the Alfred Hospital (Melbourne) for facilitating the provision of human lung samples, S. Langenbach (Dept of Pharmacology, University of Melbourne) for preliminary assistance with hydroxyproline measurements and S. Crawford (Dept of Pharmacology, University of Melbourne) for assistance with preparation of samples for electron microscopy.

\section{REFERENCES}

1 Stewart AG, Tomlinson PR, Wilson J. Airway wall remodelling in asthma: a novel target for the development of anti-asthma drugs. Trends Pharmacol Sci 1993; 14: 275-279.

2 James A. Remodelling of airway smooth muscle in asthma: what sort do you have? Clin Exp Allergy 2005; 35: 703-707.

3 Hay DW. Putative mediator role of endothelin-1 in asthma and other lung diseases. Clin Exp Pharmacol Physiol 1999; 26: 168-171.

4 Howarth PH, Knox AJ, Amrani Y, et al. Synthetic responses in airway smooth muscle. J Allergy Clin Immunol 2004; 114: S32-S50.

5 Hirst SJ, Martin JG, Bonacci JV, et al. Proliferative aspects of airway smooth muscle. J Allergy Clin Immunol 2004; 114: S2-S17.

6 Roche WR, Beasley R, Williams JH, et al. Subepithelial fibrosis in the bronchi of asthmatics. Lancet 1989; 1: 520-524.

7 Brewster CE, Howarth PH, Djukanovic R, et al. Myofibroblasts and subepithelial fibrosis in bronchial asthma. Am J Respir Cell Mol Biol 1990; 3: 507-511.

8 Schmitt-Graff A, Desmouliere A, Gabbiani G. Heterogeneity of myofibroblast phenotypic features: an example of fibroblastic cell plasticity. Virchows Arch 1994; 425: 3-24.

9 Halayko AJ, Solway J. Molecular mechanisms of phenotypic plasticity in smooth muscle cells. J Appl Physiol 2001; 90: 358-368.

10 Bramley AM, Roberts CR, Schellenberg RR. Collagenase increases shortening of human bronchial smooth muscle in vitro. Am J Respir Crit Care Med 1995; 152: 1513-1517.

11 Wilson JW, Li X, Pain MC. The lack of distensibility of asthmatic airways. Am Rev Respir Dis 1993; 148: 806-809.

12 Freyer AM, Johnson SR, Hall IP. Effects of growth factors and extracellular matrix on survival of human airway smooth muscle cells. Am J Respir Cell Mol Biol 2001; 25: 569-576.

13 Bonacci JV, Schuliga M, Harris $\mathrm{T}$, et al. Collagen impairs glucocorticoid actions in airway smooth muscle through integrin signalling. Br J Pharmacol 2006; 149: 365-373. 
14 Nguyen TT, Ward JP, Hirst SJ. $\beta_{1}$-integrins mediate enhancement of airway smooth muscle proliferation by collagen and fibronectin. Am J Respir Crit Care Med 2005; 171: 217-223.

15 Peng Q, Lai D, Nguyen TT, et al. Multiple $\beta_{1}$ integrins mediate enhancement of human airway smooth muscle cytokine secretion by fibronectin and type I collagen. J Immunol 2005; 174: 2258-2264.

16 Stewart AG, Fernandes D, Tomlinson PR. The effect of glucocorticoids on proliferation of human cultured airway smooth muscle. Br J Pharmacol 1995; 116: 3219-3226.

17 Ward JE, Harris T, Bamford T, et al. Proliferation is not increased in airway myofibroblasts isolated from asthmatics. Eur Respir J 2008; 32: 362-371.

18 Burgess JK, Oliver BG, Poniris MH, et al. A phosphodiesterase 4 inhibitor inhibits matrix protein deposition in airways in vitro. J Allergy Clin Immunol 2006; 118: 649-657.

19 Liu X, Kohyama T, Wang H, et al. Th2 cytokine regulation of type I collagen gel contraction mediated by human lung mesenchymal cells. Am J Physiol Lung Cell Mol Physiol 2002; 282: L1049-L1056.

20 Wen FQ, Skold CM, Liu XD, et al. Glucocorticoids and TGF- $\beta 1$ synergize in augmenting fibroblast mediated contraction of collagen gels. Inflammation 2001; 25: 109-117.

21 Shi-Wen X, Chen $\mathrm{Y}$, Denton $\mathrm{CP}$, et al. Endothelin-1 promotes myofibroblast induction through the ETA receptor via a rac/ phosphoinositide 3-kinase/Akt-dependent pathway and is essential for the enhanced contractile phenotype of fibrotic fibroblasts. Mol Biol Cell 2004; 15: 2707-2719.

22 Tomlinson PR, Wilson JW, Stewart AG. Inhibition by salbutamol of the proliferation of human airway smooth muscle cells grown in culture. Br J Pharmacol 1994; 111: 641-647.

23 Grange RL, Ziogas J, North AJ, et al. Selenosartans: novel selenophene analogues of milfasartan and eprosartan. Bioorg Med Chem Lett 2008; 18: 1241-1244.

24 Elsdale T, Bard J. Collagen substrata for studies on cell behavior. J Cell Biol 1972; 54: 626-637.

25 Davenport AP, Battistini B. Classification of endothelin receptors and antagonists in clinical development. Clin Sci (Lond) 2002; 103: Suppl. 48, 1S-3S.

26 Wakatsuki T, Schwab B, Thompson NC, et al. Effects of cytochalasin D and latrunculin B on mechanical properties of cells. J Cell Sci 2001; 114: 1025-1036.

27 Hirst SJ, Barnes PJ, Twort CH. Quantifying proliferation of cultured human and rabbit airway smooth muscle cells in response to serum and platelet-derived growth factor. Am J Respir Cell Mol Biol 1992; 7: 574-581.

28 Ward JE, Fernandes DJ, Taylor CC, et al. The PPAR $\gamma$ ligand, rosiglitazone, reduces airways hyperresponsiveness in a murine model of allergen-induced inflammation. Pulm Pharmacol Ther 2006; 19: 39-46.

29 Langenbach SY, Wheaton BJ, Fernandes DJ, et al. Resistance of fibrogenic responses to glucocorticoid and 2-methoxyestradiol in bleomycin-induced lung fibrosis in mice. Can J Physiol Pharmacol 2007; 85: 727-738.
30 Kimura C, Oike M, Koyama T, et al. Alterations of Ca2+ mobilizing properties in migrating endothelial cells. Am J Physiol Heart Circ Physiol 2001; 281: H745-H754.

31 Bell E, Ivarsson B, Merrill C. Production of a tissue-like structure by contraction of collagen lattices by human fibroblasts of different proliferative potential in vitro. Proc Natl Acad Sci USA 1979; 76: 1274-1278.

32 Grinnell F. Fibroblast-collagen-matrix contraction: growth-factor signalling and mechanical loading. Trends Cell Biol 2000; 10: 362-365.

33 Zhu YK, Liu X, Wang H, et al. Interactions between monocytes and smooth-muscle cells can lead to extracellular matrix degradation. J Allergy Clin Immunol 2001; 108: 989-996.

34 Roy P, Petroll WM, Chuong CJ, et al. Effect of cell migration on the maintenance of tension on a collagen matrix. Ann Biomed Eng 1999; 27: 721-730

35 Goldie RG, Henry PJ, Knott PG, et al. Endothelin-1 receptor density, distribution, and function in human isolated asthmatic airways. Am J Respir Crit Care Med 1995; 152: 1653-1658.

36 Matsumoto H, Moir LM, Oliver BG, et al. Comparison of gel contraction mediated by airway smooth muscle cells from patients with and without asthma. Thorax 2007; 62: 848-854.

37 Schuliga M, See I, Ong S, et al. Fibrillar collagen clamps lung mesenchymal cells in a non-proliferative and non-contractile phenotype. Am J Respir Cell Mol Biol 2009; 41: 731-741.

38 Panettieri RA Jr, Goldie RG, Rigby PJ, et al. Endothelin-1-induced potentiation of human airway smooth muscle proliferation: an ETA receptor-mediated phenomenon. Br J Pharmacol 1996; 118: 191-197.

39 Fang Q, Liu X, Al-Mugotir M, et al. Thrombin and TNF- $\alpha / \mathrm{IL}-1 \beta$ synergistically induce fibroblast-mediated collagen gel degradation. Am J Respir Cell Mol Biol 2006; 35: 714-721.

40 Ehrlich HP, Rajaratnam JB. Cell locomotion forces versus cell contraction forces for collagen lattice contraction: an in vitro model of wound contraction. Tissue Cell 1990; 22: 407-417.

41 Hedges JC, Dechert MA, Yamboliev IA, et al. A role for p38(MAPK)/HSP27 pathway in smooth muscle cell migration. J Biol Chem 1999; 274: 24211-24219.

42 Gerthoffer WT. Migration of airway smooth muscle cells. Proc Am Thorac Soc 2008; 5: 97-105.

43 Phillips JA, Vacanti CA, Bonassar LJ. Fibroblasts regulate contractile force independent of MMP activity in 3D-collagen. Biochem Biophys Res Commun 2003; 312: 725-732.

44 Ergul A, Portik-Dobos V, Giulumian AD, et al. Stress upregulates arterial matrix metalloproteinase expression and activity via endothelin A receptor activation. Am J Physiol Heart Circ Physiol 2003; 285: H2225-H2232.

45 Goncharova EA, Billington CK, Irani C, et al. Cyclic AMPmobilizing agents and glucocorticoids modulate human smooth muscle cell migration. Am J Respir Cell Mol Biol 2003; 29: 19-27.

46 Skold CM, Liu XD, Zhu YK, et al. Glucocorticoids augment fibroblast-mediated contraction of collagen gels by inhibition of endogenous PGE production. Proc Assoc Am Physicians 1999; 111: 249-258. 